\title{
PERENCANAAN ALTERNATIF GEOMETRIK DAN METODE PELAKSANAAN RUAS JALAN NGRAHO - NGAWI STA.14+500 - STA.19+500
}

\author{
Agung Gagah Harmawanto ${ }^{*}$, Yosef Cahyo S.P ${ }^{2}$, Sigit Winarto ${ }^{3}$. \\ 1,2,3 Fakultas Teknik, Universitas Kadiri. \\ e-mail: ${ }^{1 *}$ harmaggh@gmail.com, ${ }^{2}$ yosef.cs@unik-kediri.ac.id, \\ 3 sigit.winarto@unik-kediri.ac.id.
}

\begin{abstract}
Ngraho - Ngawi Sta. $14+500-$ Sta. $19+500$ highway is a collector connecting Bojonegoro to Ngawi Due to high traffic density, a road geometric Development is in need. The objective of this final project is to plan a good alternative geometric design-safe, comfortable, and easy to access. The required data were of topographic map and the road geometric design was based on the "Tata Cara Perencanaan Geometrik Jalan Antar Kota" General Works Standart No. 038/TBM/1997. The calculations result in Class 2 - lane collector road with one lane of $3 \mathrm{~m}$ wide having 8 turns, twists $\mathrm{PI}_{1}$ Spiral-Spiral, $\mathrm{PI}_{2}$ Spiral-Circle-Spiral, $\mathrm{PI}_{3}$ Spiral-Circle-Spiral, $\mathrm{PI}_{4}$ Spiral-Circle-Spiral, $\mathrm{PI}_{5}$ Spiral-Circle-Spiral, PI $\mathrm{I}_{6}$ Spiral-Circle-Spiral, $\mathrm{PI}_{7}$ Spiral-Circle-Spiral, and turn $\mathrm{PI}_{8}$ Spiral-Spiral shape PPV PPV 1 concave and 2 convex, concave 3 PPV.
\end{abstract}

Keywords : Planning, Geometric, Highway, Traffic.

\begin{abstract}
Abstrak
Jalan provinsi ruas Ngraho - Ngawi Sta. 14+500 - Sta. 19+500 adalah jalan kolektor yang menghubungkan kota Bojonegoro - Ngawi. Karena lalu lintasnya padat, maka perlu diadakan peningkatan geometrik jalan. Dalam laporan akhir ini penulis membuat perencanaan alternatif desain geometrik jalan yang baikaman,nyaman, dan mudah diakses oleh pengguna jalan. Data yang digunakan adalah peta topografi dan perencanaan desain geometrik jalan berpedoman oleh "Tata Cara Perencanaan Geometrik Jalan Antar Kota" Standar Bina Marga No.038/TBM/1997. Dari perhitungan diperoleh hasil sebagai berikut: kelas jalan kolektor dengan 2 lajur 1 jalur dan memiliki lebar $3 \mathrm{~m}, 8$ tikungan, tikungan $\mathrm{PI}_{1}$ Spiral-Spiral, $\mathrm{PI}_{2}$ SpiralCircle-Spiral, $\mathrm{PI}_{3}$ Spiral-Circle-Spiral, $\mathrm{PI}_{4}$ Spiral-Circle-Spiral, $\mathrm{PI}_{5}$ Spiral-Circle-Spiral, $\mathrm{PI}_{6}$ Spiral-Circle-

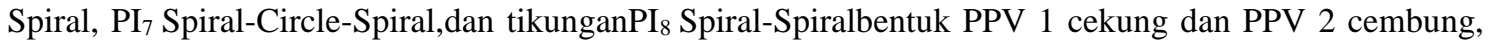
PPV 3 cekung.
\end{abstract}

Kata Kunci : Perencanaan, Geometrik, Jalan, Lalulintas. 


\section{PENDAHULUAN}

Kebutuhan akan adanya sarana transportasi merupakan satu hal yang sangat penting untuk diperhatikan pada masa sekarang ini. Seiring program pembangunan disegala bidang yang berkembang sangat pesat, maka kebutuhan akan adanya sarana transportasi merupakan hal yang sangat penting baik di kota maupun di desa [1][2][3]. Disamping itu juga mengingat transportasi merupakan urat nadi pembangunan yang berperan sangat penting dalam pengembangan potensi suatu wilayah, terutama bagi wilayah yang sedang berkembang sehingga dicapai tingkat perkembangan yang merata disemua wilayah. Pembangunan jalan di maksudkan untuk mempermudah hubungan dari suatu wilayah ke wilayah lain serta akses distribusi barang dan jasa,.

Untuk daerah perkotaan, jalan raya merupakan aspek penting untuk mendukung segala aktivitas perekonomian, pendidikan, pemerintahan, dan lain-lain. Karena itu tingkat kepadatan jalan perkotaan sangat tinggi dan jumlah kendaraan melebihi kapasitas yang ada, sehingga pelayanan jalan menurun dari kapasitas yang ada, sama halnya dengan yang ada di ruas jalan di kota Bojonegoro dengan adanya indikasi kemacetan dibeberapa tempat [3][4][5].

Mengingat sentra-sentra perdagangan, pemerintahan, dan pendidikan yang tidak merata dan terpusat di daerah kota mengakibatkan terjadinya kemacetan dan sering menimbulkan kecelakaan lalu lintas [6][7]. Di sisi lain jalan penghubung antara kabupaten Ngawi dengan daerah barat kabupaten Bojonegoro juga semakin padat arusnya sehingga menambah kemacetan, [8][9]. Untuk mengatasi hal tersebut pemerintah daerah kabupaten Bojonegoro merencanakan jalur alternatif sekaligus sebagai salah satu bentuk pengembangan jalur transportasi di wilayah Jawa Timur. Mengacu penjelasan di atas, Penyusun merumuskan beberapa permasalahan dalam tugas akhir yang berjudul PERENCANAAN ALTERNATIF GEOMETRIK DAN METODE PELAKSANAAN RUAS JALAN NGRAHO - NGAWI STA. 14+500 - STA. 19+500. Perencanaan geometrik jalan ini berdasarkan dari peta topografi lengkap dengan kontur yang akan menjadi data peta dasar perencanaan jalan, dengan skala tidak kurang dari $1: 10.000$ (skala yang lain misal $1: 2.500,1: 5.000$ ), perbedaan tinggi setiap garis kontur tidak boleh lebih dari $5 \mathrm{~m}$.

\section{METODE PENELITIAN}

\subsection{Lokasi Penelitian.}

Penelitian ini dilakukan di ruas jalan Ngraho-Ngawi Kabupaten Bojonegoro.

\subsection{Pengertian Geometrik Jalan.}

Perencanaan geometrik jalan adalah perencanaan seluruh trase jalan. Meliputi 
beberapa komponen yang disesuaikan dengan kelengkapan seluruh data yang ada dari hasil survey lapangan dan telah dianalisis serta berdasar pada ketentuan yang berlaku.

jalan adalah prasarana transportasi darat yang meliputi segala bagian jalan, termasuk bangunan pelengkap dan perlengkapannya yang diperuntukkan bagi lalu lintas, yang berada pada permukaan tanah, di atas permukaan tanah, di bawah permukaan tanah dan/atau air, serta di atas permukaan air, kecuali jalan kereta api, jalan lori, dan jalan kabel [10] [11].

\subsection{Klasifikasi Jalan.}

a. Jalan Arteri

Jalan Arteri adalah trase jalan yang menghubungkan antar kota satu yang berjajar atau jalan yang menghubungkan kota satu dengan kota dua, [12].

b. Jalan Kolektor

Jalan Kolektor adalah trase jalan yang menghubungkan antar kota dua dengan kota tiga, atau kota satu dengan kota tiga [13].

c. Jalan Lokal

Jalan Lokal adalah trase jalan yang menghubungkan kota satu dengan persil, kota dua dengan persil, kota tiga dengan kota lainnya, kota ketiga dan kota di bawahnya, [12].

Ada beberapa syarat yang harus dimiliki oleh Jalan Lokal yaitu :

\subsubsection{Klasifikasi Menurut Kelas Jalan}

1. Klasifikasi menurut mutu jalan berhubungan dengan kapasitas jalan untuk menerima beban kendaraan, dinyatakan dalam muatan sumbu terberat (MST) dengan satuan ton

2. Klasifikasi menurut mutu jalan dan ketentuannya serta hubungannya dengan klasifikasi menurut mutu jalan dapat dilihat dalam Tabel 1 Klasifikasi jalan menurut kelas jalan

Tabel 1. Klasifikasi jalan menurut kelas jalan

\begin{tabular}{|c|c|c|}
\hline Jenis Jalan & Kelas & $\begin{array}{c}\text { Muatan Sumbu Terberat MST } \\
\text { (ton) }\end{array}$ \\
\hline \multirow{2}{*}{ Arteri } & I & $>10$ \\
& II & 10 \\
Kolektor & III & 8 \\
\hline \multirow{2}{*}{ III A } & 8 \\
\hline
\end{tabular}

Sumber : [13] RSNI Geometrik Jalan Perkotaan No.T/14/2004

Pada Tabel 1. Memperlihatkan klasifikasi jalan menurut kelas jalan. Pada Jalan Arteri Kelas I memiliki MST >10 ton, kelas II memiliki MST 10 ton, kelas III memiliki MST 8 ton. 
Dan jalan Kolektor pada kelas III A memiliki MST 8 ton, kelas IIIB memiliki MST 8 ton.

\subsubsection{Klasifikasi Menurut Medan Jalan}

1. Medan jalan digolongkan sesuai kondisi mayoritas kemiringan medan yang diukur tegak lurus garis kontur.

2. Golongan menurut track jalan untuk perencanaan geometri bisa dilihat dalam Tabel 2 Klasifikasi jalan menurut medan jalan.

3. Kesamaan situasi track yang diproyeksikan harus memperhitungkan Kesamaan situasi track menurut rencana trase jalan dengan meninggalkan perubahan di bagian kecil dari komponen rencana jalan tersebut.

Tabel 2. Klasifikasi jalan menurut medan jalan

\begin{tabular}{|c|c|c|c|}
\hline No. & Jenis Medan & Notasi & Kemiringan Medan (\%) \\
\hline 1. & Datar & D & $<3$ \\
2. & Perbukitan & B & $3-25$ \\
3. & Pegunungan & G & $>25$ \\
\hline
\end{tabular}

Sumber : [15] Tata Cara Perencanaan Geometrik Jalan Antar Kota,1997

Pada Tabel 2. Klasifikasi jalan menurut medan jalan terdapat 3 jenis medan yaitiu Datar dengan kemiringan medan $<3 \%$, Perbukitan dengan kemiringan $3-25 \%$, Pegunungan $>25 \%$.

\subsection{Volume Lalu Lintas Harian Rencana.}

Volume lalu lintas sangat erat hubungannya dengan lebar perkerasan jalan dan juga dalam menentukan jumlah lajur. Apabila volume lalu lintas padat membutuhkan dimensi perkerasan jalan yang lebih lebar dan juga sebaliknya.

$$
\text { VJR }=\text { VLHR } x \frac{\mathrm{K}}{\mathrm{F}}
$$

Keterangan :

$\mathrm{K}$ : Faktor lalu lintas jam puncak/sibuk

$\mathrm{F}$ : Faktor variasi angka kendaraan / 1/4 jam dalam 1 jam.

\subsection{Kecepatan rencana.}

1. Kecepatan rencana, VR, di suatu trase jalan yaitu kecepatan yang digunakan untuk dasar perencanaan geometri jalan yang memungkinkan kendaraan bisa bergerak dengan aman dan enjoy serta dalam keadaan cuaca yang cerah, lalu lintas yang lancar, dan pengaruh sisi jalan yang tidak berarti.

2. $\mathrm{V}_{R}$ untuk setiap manfaat jalan bisa diperoleh dari Tabel 3 Kecepatan Rencana. 
3. Untuk situasi track yang exstrem, VR suatu bagian jalan bisa diturunkan dengan syarat penurunan VR tidak lebih besar dari $20 \mathrm{~km} / \mathrm{jam}$.

Tabel 3. Kecepatan Rencana

\begin{tabular}{|c|c|c|c|}
\hline \multirow{2}{*}{ Fungsi } & \multicolumn{3}{|c|}{ Kecepatan Rencana, VR' Km/jam } \\
\cline { 2 - 4 } & Datar & Bukit & Pegunungan \\
\hline Arteri & $70-120$ & $60-80$ & $40-70$ \\
\hline Kolektor & $60-90$ & $50-60$ & $30-50$ \\
\hline Lokal & $40-70$ & $30-50$ & $20-30$ \\
\hline
\end{tabular}

Sumber : [15] Tata Cara Perencanaan Geometrik Jalan Antar Kota,1970

Pada Tabel3. Kecepatan rencana pada jalan Arteri didaerah datar 70-120 km/jam, bukit $60-80 \mathrm{~km} / \mathrm{jam}$, pegunungan 40-70 km/jam. Pada jalan Kolektor didaerah datar 60-90 $\mathrm{km} / \mathrm{jam}$, bukit 50-60 km/jam, pegunugan 30-50 km/jam, jalan Lokal pada daerah datar 40$70 \mathrm{~km} / \mathrm{jam}$, bukit 30-50 km/jam, pegunungan 20-30 km/jam.

\subsection{Alinemen Horisontal}

Alinemen horisontal atau trase jalan yaitu garis proyek disumbu jalan yang tegak lurus di bidang peta yang sering pula disebut dengan peta situasi jalan atau denah. Pada perencanaan alinemen horizontal jalan, umumnya akan dijumpai dua bagian jalan, yaitu segmen lurus dan segmen lengkung atau umumnya yang dinamakan tikungan.

Untuk menghitung jari-jari minimum dan derajat lengkung dapat menggunakan rumus sebagai berikut :

$$
R_{\text {min }}=\frac{V r^{2}}{127\left(E_{\max }+F_{\max }\right)}
$$

Keterangan :

$$
\begin{aligned}
\mathrm{Rmin} & =\text { Jari-jari minimum } \\
\mathrm{Vr} & =\text { Kecepatan rencana }(\mathrm{km} / \mathrm{jam}) \\
\mathrm{E}_{\max } & =\text { Superelevasi maksimum }(\%) \\
\mathrm{F}_{\max } & =\text { Koefisien gesekan maksimum dimana } \mathrm{F}_{\max } \\
& =<80 \mathrm{Kph} \rightarrow-0.000625 \times \mathrm{V}+\mathrm{c} .192 \\
& =80-112 \mathrm{Kph} \rightarrow-0.00125 \times \mathrm{V}+0.24
\end{aligned}
$$

\subsubsection{Full-Circle (FC)}

Lengkung Full circle yaitu jenis tikungan yang hanya terdiri dari segmen bentuk lingkaran saja. Tikungan Full Circle hanya dipakai untuk R (jari-jari lingkaran) yang lebar agar tidak terjadi retakan (crack), karena nilai R kecil maka dibutuhkan superelevasi yang besar, [16]. 


\subsubsection{Lengkung Spiral - Circle - Spiral (SCS)}

a. Waktu lengkung SCS digunakan pada tikungan yang mempunyai sudut defleksi $\Delta>15^{0}$ dan biasanya mempunyai lengkung peralihan.

b. Berdasarkan antisipasi gaya sentrifugal.

c. Tingkatan perubahan pencapaian, [16].

\subsubsection{Spiral-Spiral ( S-S )}

Lengkung yang cuma terdiri dari spiral dan spiral saja tanpa adanya bentuk circle dan juga bisa di namakan model SCS tanpa circle.

\subsection{Diagram Superelevasi}

Superelevasi yaitu suatu kemiringan melintang jalan pada daerah tikungan. Untuk bagian jalan lurus, jalan mempunyai kemiringan melintang yang dinamakan lereng normal atau Normal Trawn yaitu diambil minimum $2 \%$ sebelah kiri dan sebelah kanan AS jalan, [17].

Sedangkan yang dimaksud diagram superelevasi yaitu suatu cara untuk menampilkan nilai superelevasi dan lereng normal menuju kemiringan melintang (superelevasi). Diagram superelevasi di ketinggian bentuknya tergantung dari model lengkung yang berkaitan.

\subsection{Alinemen Vertikal}

Alinemen vertikal yaitu perpotongan bidang vertikal dengan bidang permukaan perkerasan jalan melalui sumbu-sumbu jalan dan lajur 2 arah atau melalui pinggir dalam setiap perkerasan untuk jalan dengan median disebut penampang memanjang, [19].

\subsubsection{Kelandaian Maksimum}

Kelandaian dapat dibagi menjadi :

a. Kelandaian maksimum, ditujukan untuk kendaraan bisa melaju lurus tanpa kehilangan kecepatan kendaraan. Kelandaian maksimum untuk setiap VR diputuskan bisa dilihat dalam Tabel 4 Kelandaian maksimum yang diizinkan.

b. Kelandaian maksimum didasarkan pada kecepatan kendaraan yang bermuatan penuh yang mampu melaju dengan penurunan kecepatan tidak boleh lebih dari separuh kecepatan awal tanpa harus menggunakan gigi rendah.

Tabel 4. Kelandaian maksimum yang diizinkan

\begin{tabular}{|c|c|c|c|c|c|c|c|c|}
\hline $\mathrm{V}_{\mathrm{R}}(\mathrm{km} / \mathrm{jam})$ & 120 & 110 & 100 & 80 & 60 & 50 & 40 & $<40$ \\
\hline Kelandaian Maksimal (\%) & 3 & 3 & 4 & 5 & 8 & 9 & 10 & 10 \\
\hline
\end{tabular}

Sumber : [15] Tata Cara Perencanaan Geometrik Jalan Antar Kota,1970 
Pada Tabel 4. Kelandaian maksimum yang diizinkan pada kecepatan $120 \mathrm{~km} / \mathrm{jam}$ kelandaiannya 3\%, pada kecepatan 110 kelandaiannya 3\%, pada kecepatan 100 kelandaiannya 4\%, pada kecepatan 80 kelandaiannya 5\%, pada kecepatan 60 kelandaiannya 8\%, pada kecepatan 50 kelandaiannya 9\%, pada kecepatan 40 kelandaiannya 10\%, pada kecepatan <40 kelandaiannya $10 \%$.

\subsubsection{Lengkung Vertikal}

Lengkung vertikal dihitung untuk mengubah secara berurutan perubahan dari dua jenis mutu jalan pada arah memanjang jalan di setiap lokasi yang diperlukan. lengkung vertikal dapat dibedakan menjadi dua jenis :

1. Lengkung vertikal cekung yaitu lengkung pada titik perpotongan antara kedua tangen berada dibawah permukaan jalan.

2. Lengkung vertikal cembung yaitu lengkung pada titik perpotongan antara dua tangen berada diatas medan jalan yang bersangkutan.

\subsection{Koordinasi Alinemen}

Koordinasi alinemen pada perencanaan teknik jalan direncanakan untuk menjamin perencanaan teknik jalan yang baik, efisien dan menghasilkan keamanan serta rasa nyaman bagi pengemudi kendaraan yang melalui jalan tersebut.

Maksud koordinasi dalam hal ini adalah menggabungkan beberapa elemen perencanaan geometrik jalan yang terdiri dari perencanaan. Alinemen horisontal, alinemen vertikal, dan potongan melintang jalan yaitu elemen - elemen jalan keluaran perencanaan harus dikoordinasikan dengan baik sehingga mendapatkan suatu model jalan yang baik dalam artian mempermudah pengendara mengoperasikan kendaraannya dengan aman dan nyaman, [20].

\subsection{Jarak Pandang}

Jarak pandang yaitu suatu jarak yang diperlukan oleh pengemudi kendaraan pada saat mengemudi sedemikian rupa sehingga jika pengendara melihat suatu rintangan yang membahayakan, pengendara bisa bertindak sesuatu untuk menyelamatkan diri dari rintangan tersebut dengan aman. Jarak pandang terbagi menjadi dua bagian yaitu Jarak Pandang Henti (Jh) dan Jarak Pandang Mendahului (Jd).

\subsubsection{Jarak Pandang Henti (Jh)}

Jarak Pandang Henti yaitu jarak minimun yang diperlukan setiap pengemudi kendaraan untuk memperlambat laju kendaraannya dengan aman begitu melihat adanya halangan didepannya. Jarak pandang henti apat dilihat pada Tabel 5. 
Tabel 5. Jarak pandang henti (Ss) minimum dengan kelandaian

\begin{tabular}{|c|c|c|c|c|c|c|c|c|c|c|c|c|}
\hline \multirow{2}{*}{$\begin{array}{c}\mathrm{V}_{\mathrm{R}} \\
(\mathrm{km} / \mathrm{jam})\end{array}$} & \multicolumn{10}{|c|}{ Turunan } \\
\cline { 2 - 14 } & \multicolumn{10}{|c|}{ Tarak Pandang Henti (m) } \\
\cline { 2 - 14 } & $1 \%$ & $2 \%$ & $3 \%$ & $4 \%$ & $5 \%$ & $6 \%$ & $1 \%$ & $2 \%$ & $3 \%$ & $4 \%$ & $5 \%$ & $6 \%$ \\
\hline 120 & 252 & 257 & 263 & 269 & 275 & 281 & 243 & 238 & 234 & 230 & 227 & 223 \\
\hline 100 & 187 & 190 & 194 & 198 & 203 & 207 & 180 & 177 & 174 & 172 & 169 & 167 \\
\hline 80 & 131 & 133 & 136 & 138 & 141 & 144 & 127 & 125 & 123 & 121 & 120 & 118 \\
\hline 60 & 84 & 86 & 87 & 88 & 90 & 92 & 82 & 81 & 80 & 79 & 78 & 77 \\
\hline
\end{tabular}

Sumber : [18] Geometri Jalan Bebas Hambatan Untuk Jalan Tol, 2009

Pada Tabel 5. Jarak pandang henti (Ss) minimum dengan kelandaian yang berada di turunan serta tanjakan pada saat $\mathrm{V}_{\mathrm{R}} 120,100,80,60 \mathrm{~km} / \mathrm{jam}$ serta nilai persentase kelandaian mulai dari $1 \%$ sampai $6 \%$.

\subsubsection{Jarak Pandang Mendahului (Jd)}

Jarak pandang mendahului yaitu jarak yang menjadikan hal kendaraan mendahului kendaraan lain di hadapannya dengan aman hingga kendaraan itu kembali ke lajur awal (lihat Gambar 1).

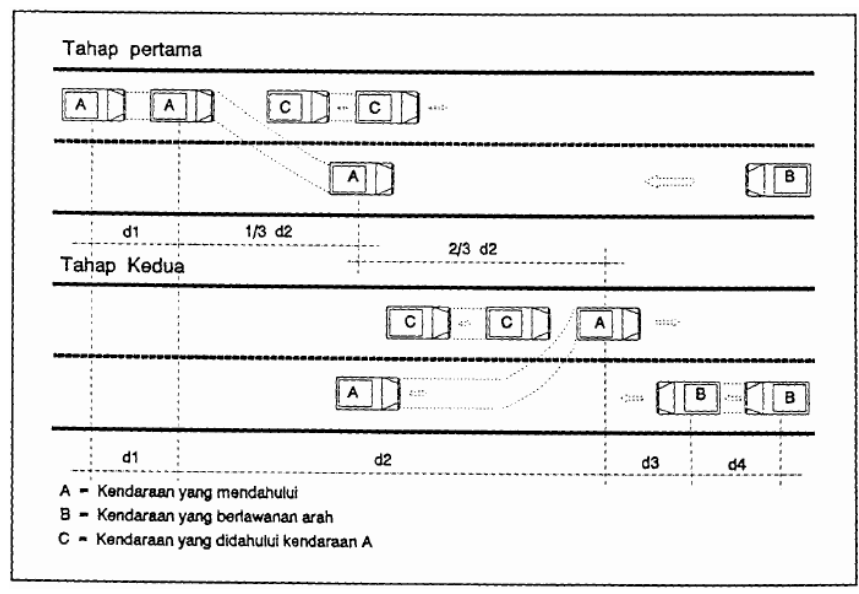

Gambar 1. Jarak pandang mendahului

Pada Gambar 1. Diperlihatkan jarak untuk mendahului kendaraan lain dihadapannya dengan aman sehingga kendaraan itu kembali ke jalur awal dengan aman. 


\section{HASIL DAN PEMBAHASAN}

\subsection{Hasil Perhitungan Alinemen Horisontal}

Berdasarkan perhitungan alinyemen horizontal didapatkan 8 tikungan, yaitu:

1. Tikungan PI 1 Spiral-Spiral, lengkung PI $1=142,220 \mathrm{~m}$.

2. tikungan PI 2 Spiral-Circle-Spiral, lengkung PI $2=168,48 \mathrm{~m}$.

3. tikungan PI 3 Spiral-Circle-Spiral, lengkung PI $3=161,798 \mathrm{~m}$.

4. tikungan PI 4 Spiral-Circle-Spiral, lengkung PI $4=180,080 \mathrm{~m}$.

5. tikungan PI 5 Spiral-Circle-Spiral, lengkung PI $5=176,601 \mathrm{~m}$.

6. tikungan PI 6 Spiral-Circle-Spiral, lengkung PI $6=175,198 \mathrm{~m}$.

7. tikungan PI 7 Spiral-Circle-Spiral, lengkung PI $7=176,701 \mathrm{~m}$.

8. tikungan PI 8Spiral-Spiral, lengkung PI $8=142,220 \mathrm{~m}$.

\subsection{Hasil Perhitungan Alinemen Horisontal}

Berdasarkan perhitungan alinyemen vertikal didapatkan 3 lengkung vertikal. yaitu :

1. lengkung PVI 1 = cekung, PVI 1 Sta.15+476-Sta.15+524 = $48 \mathrm{~m}$

2. lengkung PVI $2=$ cembung, PVI 2 Sta.16+086,465-Sta.16+134,465 $=48 \mathrm{~m}$

3. lengkung PVI $3=$ cekung, PVI 3 Sta.17+976-Sta.18+024=48m

\section{KESIMPULAN}

Dari hasil perencanaan dan perhitungan geometrik pada ruas jalan Ngraho - Ngawi Sta. $14+500$ - Sta. 19+500, dapat disimpulkan sebagai berikut :

1. Berdasarkan perhitungan alinyemen horizontal didapatkan 8 tikungan, yaitu: Tikungan PI 1 Spiral-Spiral, tikungan PI 2 Spiral-Circle-Spiral, tikungan PI 3 Spiral-Circle-Spiral, tikungan PI 4 Spiral-Circle-Spiral, tikungan PI 5 Spiral-Circle-Spiral, tikungan PI 6 Spiral-CircleSpiral, tikungan PI 7 Spiral-Circle-Spiral, dan tikungan PI 8Spiral-Spiral.Panjang lengkung PI $1=142,220 \mathrm{~m}$, lengkung PI $2=168,48 \mathrm{~m}$, lengkung PI $3=161,798 \mathrm{~m}$, lengkung PI $4=$ 180,080 m, lengkung PI $5=176,601 \mathrm{~m}$, lengkung PI $6=175,198 \mathrm{~m}$, lengkung PI $7=176,701$, lengkung PI $8=142,220 \mathrm{~m}$.

2. Berdasarkan perhitungan alinyemen vertikal didapatkan 3 lengkung vertikal. yaitu lengkung PVI 1 = cekung, PVI 2 cembung, dan lengkung PVI 3 cekung. Panjang lengkung PVI 1 Sta.15+476-Sta.15+524 = $48 \mathrm{~m}$, PVI 2 Sta.16+086,465-Sta.16+134,465 = $48 \mathrm{~m}$, PVI 3 Sta. $17+976-$ Sta. $18+024=48 \mathrm{~m}$.

3. Metode pelaksanaan geometrik ruas jalan Ngraho - Ngawi Sta. $14+500-$ Sta. $19+500$ menggunakan metode penentuan posisi horizontal yang menggunakan metode Polar. 


\section{SARAN}

Demi mendapatkan penulisan tugas akhir yang baik dan benar standar yang digunakan sebagai dasar perhitungan dan perencanaan harus paten sehingga penulisan laporan akhir terarah dengan mengacu pada standar tersebut. Serta tata penulisan yang telah diberikan oleh jurusan sebaiknya diperhatikan dengan benar agar sesuai dengan yang di inginkan.

\section{UCAPAN TERIMAKASIH}

Dalam penyusunan artikel ini, penulis ucapkan terimakasih kepada dosen pembimbing dan Universitas Kadiri. Penulis berharap agar artikel ini dapat bermanfaat bagi pembaca.

\section{DAFTAR PUSTAKA}

[1] A. Kurniawan, S. Winarto, and Y. C. S. P, "STUDI PERENCANAAN PENINGKATAN JALAN PADA RUAS JALAN JALUR LINTAS SELATAN GIRIWOYO - DUWET STA. 10+000 - STA. 15+000," Jurmateks, vol. 2, no. 1, pp. 39-50, 2019.

[2] S. Awiyaningsih, H. Moetriono, and D. T. Sipil, "ANALISIS DAMPAK LALU LINTAS AKIBAT PEMBANGUNAN MALL LAGOON AVENUE SUNGKONO TERHADAP KINERJA SIMPANG DI JL MAYJEND SUNGKONO - HR MUHAMMAD SURABAYA,” Tek. Eng. Sains J., vol. 2, no. 2, pp. 131-134, 2018.

[3] A. D. Limantara, A. I. Candra, and S. W. Mudjanarko, "Manajemen Data Lalu Lintas Kendaraan Berbasis Sistem Internet Cerdas Ujicoba Implementasi Di Laboratorium Universitas Kadiri,” 2017.

[4] E. N. Julianto, "Hubungan Antara Kecepatan, Volume Dan Kepadatan Lalu Lintas Ruas Jalan Siliwangi Semarang,”J. Tek. Sipil dan Perenc., vol. 12, no. 2, pp. 151-160, 2010.

[5] A. I. Candra et al., "PENGECEKAN KELAYAKAN BANGUNAN GEDUNG SMA NEGERI 1 KOTA KEDIRI YANG DIGUNAKAN UNTUK AKTIFITAS,” Ukarst $J$. Univ. Kadiri Ris. Tek. Sipil, vol. 2, no. 2, pp. 108-116, 2019.

[6] A. Y. Nurkafi, S. Winarto, and A. I. Candra, "ANALISA KINERJA SIMPANG TAK BERSINYAL JALAN SIMPANG BRANGGAHAN NGADILUWIH KABUPATEN,” Jurmateks, vol. 2, no. 1, pp. 164-178, 2019.

[7] A. Susanto, Y. C. S. P, and S. Winarto, "STUDI PERENCANAAN JEMBATAN CUMPLENG DENGAN METODE PRATEKAN DI KEC. SLAHUNG KABUPATEN PONOROGO,” Jurmateks, vol. 1, no. 2, pp. 172-181, 2018.

[8] R. Pramanasari, N. Qomariyah, D. Purwanto, and E. Yilipriyo, "PENERAPAN MANAJEMEN LALU LINTAS SATU ARAH PADA RUAS JALAN SULTAN AGUNG - SISINGAMANGARAJA - DR.WAHIDIN KOTA SEMARANG UNTUK 
PEMERATAAN SEBARAN BEBAN LALU LINTAS,” J. KARYA Tek. SIPIL, vol. 3, no. 1, pp. 142-153, 2014.

[9] M. Atho 'ur Rohman, D. Kartikasari, K. Kunci, and : Kemacetan, "ANALISA KEMACETAN LALU LINTAS PADA PASAR TRADISIONAL DI RUAS JALAN SEKARAN-MADURAN," J. CIVILA, vol. 1, no. 2, pp. 1-6, 2016.

[10] D. Indratmo, "Kajian Kapasitas Jalan dan Derajat Kejenuhan Lalu-Lintas di Jalan Ahmad Yani Surabaya," vol. 1, pp. 25-31, 2006.

[11] O. Z. Tamin, Perencanaan dan Pemodelan Transportasi, Edisi Kedua. 2000.

[12] A. Kurniawan, J. T. Sipil, and U. Kadiri, "STUDI PERENCANAAN PENINGKATAN JALAN PADA RUAS JALAN JALUR LINTAS SELATAN GIRIWOYO -."

[13] B. A. Harsono, S. Winarto, and Y. C. S, "PERENCANAAN PENINGKATAN JALAN PADA RUAS JALAN PACITAN-NGADIROJO,” Jurmateks, vol. 1, no. 2, pp. 291-302, 2018.

[14] Desutama, R. 2007. Dasar Dasar Perencanaan Geometrik Jalan Antar Kota. Bugi : Bandung.

[15] RSNI No. T/14 Tentang Geometrik Jalan Perkotaan, 2004, Badan Standardisasi Nasional Indonesia.

[16] Tata Cara Perencanaan Geometrik Jalan Antar Kota, 1997, Ditjen Bina Marga, DPU.

[17] Tata Peraturan Perencanaan Geometrik Jalan Raya, 1970, Ditjen Bina Marga, DPU.

[18] Sukirman, Silvia. 1999. Dasar Dasar Perencanaan Geometrik Jalan. Nova : Bandung.

[19] Standar Perencanaan Geometrik Untuk Jalan Perkotaan, 1992, Ditjen Bina Marga, DPU.

[20] Geometri Jalan Bebas Hambatan Untuk Jalan Tol, 2009, Ditjen Bina Marga, DPU.

[21] UU.RINo. 38 Tahun 1980 Tentang Jalan, Departemen Pekerjaan Umum.

[22] PP No. 34 Tahun 2006Tentang Jalan, Departemen Pekerjaan Umum. 